many, and it was marvellous to think that, owing to their response, by the time the war was at its height England was Germany's equal, if not her superior, in chemical warfare. The nation must not again be cut off from the essential means of defence, for the possibilities of war must always be remembered. To the chemist the future prospects are limitless; the discovery of new substances, the shortening of processes, economy-all these lie in his hands. The Chemical Society is doing valuable work because it exists for the general advancement of chemical science. Lord Moulton then referred to the valuable services rendered to the country by Sir William Pope in the problems connected with explosives, in the production of poisonous gases, and in the realm of photography.

In replying, Sir William Pope stated that the society numbered some 3500 members, and though it was nearly eighty years of age, it was not the age of decrepitude. It was still prepared to produce new methods for stimulating scientific work and scientific effort. He referred to Lord Moulton as the greatest chemical manufacturer of this or any other day, and chemists feel honoured at having been made an essential part of the stupendous weapon for destruction in the forging of which Lord Moulton had played so large a part. All the resources of science had been utilised in the war without scrutiny of cost, and the result had been worth the expenditure. Unless the same resources are used in the struggle before us to develop and promote, not only applied, but pure science, then our country will fall behind. It lies with our leaders to determine to what extent science will exist in the coming great wave of intellectual and material progress throughout the world. The nation must be prepared to pour out treasure into our educational establishments for securing the potential young energy of the country and of directing it into scientific channels, and money must be poured into our universities and colleges to stimulate scientific research. Whether it be pure or applied knowledge, the dividend paid will be enormous. The great object we have in view is the increase of human knowledge, and this can be achieved only by the expenditure of large sums of money.

Prof. H. E. Armstrong, in proposing the toast of "Our French Colleagues," referred to previous exchanges of courtesies between French and English chemists, and whilst this was the first time that the French Chemical Society had been officially represented at our anniversary dinner, he hoped that it would become a regular practice in the future. In replying, $\mathrm{Dr}$. C. Poulenc expressed the great pleasure felt by himself and his colleagues in being invited to take part in the first public function held by the Chemical Society since $19 \mathrm{I} 4$, for they realised that such an invitation set yet another seal on the bond of sympathy existing between the two nations.

The president then proposed "His Majesty's Forces," to which I.t.-Gen. Sir W. T. Furse, Niaster of the Ordnance, made acknowledgment.

Sir James J. Dobbie, president-elect, in proposing the toast of "The Guests," referred to the pleasure the society felt in seeing such a representative gathering of guests, and though it might seem difficult to bring them all into one toast, owing to the interests they represent being so diverse, the chemist had been closely associated with them all during the period of the war. The Right Hon. Herbert A. L. Fisher, in responding for the Board of Education, referred to the place of science in national education. Though we had arrears to make up and wanted more money, more teachers, and more learners for science, in the main the battle had been won. He was of the opinion that unless the country was provided with a large and generous scheme of education, a number of NO. 2579, VOL. IO3] talents which might be educated to a high pitch of accomplishment would be lost. Unless the community realises that science has its message, its value, that it ought to be encouraged, and that no money spent on science is wasted, science will never be in a satisfactory and wholesome condition. Sir Aston Webb replied for Art, and Sir J. J. Thomson for Science.

\section{ENERGY TRANSMISSION.}

$T \mathrm{WO}$ or three years ago a Rumanian engineer, Mr. Constantinesco, brought to this country a remarkable new method of transmitting energy. A pipe filled with water or a similar fluid is used. Vibrations of the nature of sound-waves are produced mechanically at one end of the pipe, and the energy of these is recovered at the other end as mechanical energy. As there is no general movement of translation of the mass of fluid, little is lost and the efficiency of transmission is high. The energy recovered can be applied to any mechanical operation. The method has been said to be an alternative to electrical transmission, and, in a sense, this is true. Certainly it will find a field in which it will compete with other modes of doing work at a distance.

Researches have been going on during the war, and many devices have been perfected. But it has been necessary to observe secrecy as to what has been done and what is contemplated. It is known that one im. portant invention made possible by the Sonic system of transmission is the C.C. synchronising gear on aeroplanes, which arrests the action of a machine-gun while a propeller-blade is in the line of fire, so that 2000 bullets per minute can be discharged through a propeller revolving at 1000 to 2000 r.p.m.

From a statement in the Times of March 27 it appears that works have been established at West Drayton by the Government which will serve as a laboratory to enable Mr. Constantinesco to develop his inventions. These works were recently visited by Queen Mary, the Queen of Rumania, and a distinguished company, who followed with great attention a demonstration of the applications of the new system to various industrial purposes. Although little has so far been made public, it is known that $\mathrm{Mr}$. Constantinesco has shown remarkable ingenuity and patience in devising means for applving the Sonic system to industrial operations, and he has accomplished enough to prove that his method is of the highest possible interest.

\section{THE PROBLEM OF RADIO-ACTIVE LEAD.1}

II.

$\mathrm{I}^{\mathrm{T}}$ appears, then, that 206 , the value pertaining to uranium-lead, is a very reasonable value.

But, as has been repeatedly pointed out, ordinary lead, constituting the vast bulk of the lead in the world, has without doubt a much higher atomic weight, $207 \cdot 2$, not to be expected from either of the lines of reasoning just given. In order to test the uniformity of this circumstance, Baxter, with the help of one of his assistants, investigated ordinary lead from non-uraniferous ores from many parts of the world, and discovered that the constancy of its quantitative behaviour is as striking as that of copper or silver. His figures agreed very closely, within the limit of error of experimentation, with those obtained as a part of the present comparison of the two kinds

I Presidential Address to the American Association for the Advancement of Science, Baltimore, December, 1918, by Prof. Theodore W. Richards. Continued from p. 78 
of lead, so that there could be no question as to lack of identity of methods or precautions.

Before leaving the subject of the relative atomic weights of these two types of lead, it is not without interest to note the exact absolute weights of the atoms. If, as we have excellent reason for believing on the basis of the brilliant work of Prof. R. A. Millikan, a so-called gram-atom (the atomic weight in grams) contains $606 \cdot 2$ sextillion actual atoms, the weights of the atoms of the two kinds of lead must be respectively 342 and 340 septillionths of a gram. 'Their extreme smallness as regards bulk may perhaps best be inferred from the consideration that the smallest object visible as a point in the common microscope has a diameter probably about one thousand times as great as an atom of lead. ${ }^{2}$

Evidently, on the basis of the quantitative results just exhibited, we must admit that there is at least one real difference between radio-active lead and the common metal. Are there other differences?

A question as to the density of each substance, and therefore as to the bulk occupied by the respective atoms, at once arises. Since the atom of uraniumlead weighs less than the other, it must occupy less space, supposing that it has the same density; or else it must have less density, supposing that it should occupy the same space. The identity of the chemical behaviour of the two types of lead suggests the probability of the latter alternative, and this was, therefore, assumed by Soddy; but experimental proof was evidently desirable. Therefore an extended investigation of the density of the various kinds of lead was carried out likewise in the Gibbs Memorial Laboratory. As a matter of fact, the densities of the several specimens were found to be very nearly proportional to their atomic weights; that is to say, the bulk of the atom of radio-active lead is almost exactly the same as the bulk of the atom of ordinary lead, although the weights of these atoms are so markedly different.

\section{Densities and Atomic Volumes.}

$\begin{array}{llccc} & & \begin{array}{c}\text { Atomic } \\ \text { weight }\end{array} & \text { Density } & \begin{array}{c}\text { Atomic } \\ \text { volume }\end{array} \\ \text { Pure uranio-lead } & \ldots & 206 \cdot 08 & \text { II.273 } & \text { I8.28I } \\ \text { Australian mixture } \ldots & 206 \cdot 34 & \text { II.289 } & \text { I8.278 } \\ \text { Pure common lead } \ldots & 207 \cdot 19 & \text { II.337 } & \text { I8.277 }\end{array}$

A distinctive property of elementary substances, which has always been supposed to be concerned more or less definitely with the atomic weight, is the spectrum, depending upon the wave-lengths of light emitted by the vapour. But, surprisingly enough, the spectrum lines produced by these two sorts of lead, when heated to the high temperature of the electric arc, are so precisely alike, both as to their wavelengths and their intensities, that no ordinary spectrum analysis shows any difference whatever. This has been proved by careful experiments at Harvard and elsewhere. A and B were from two different specimens of radio-active lead, $\mathrm{C}$ from ordinary lead, all very carefully purified. The range covered is about from 3000 to 2000 wave-length-far in the ultra-violet. Very recently Prof. W. D. Harkins, of Chicago, and two assistants have detected, with a very extended grating spectrum, an exceedingly minute shift (o.000 I per cent. of the wavelength-an amount far too small to be shown by the spectra exhibited) of one of the lines. The wonder is, not that there should be a difference, but rather that they should be so very nearly identical. Evidently the very considerable difference in the atomic weight produces only a barely perceptible effect on the wave-

2 If the smallest object visible in a microscope could be enlarged to the dots on the letters $i$, or the periods, in the type above. lengths of light emitted by the several isotopic forms of a given element, although a less difference in atomic weight between two different elements (for example, cobalt and nickel) is concomitant with utterly divergent spectra.

Another very interesting question, involving the relations of substance both to light and to weight (or rather density), is its refractive index. All the formulæ relating to molecular refraction involve the density of the substance concerned. In the case under consideration, do the differing weights of the atoms, and therefore the differing densities, of the same compounds of the two kinds of lead, affect the refractive indices of the salts? Is the refractive index of a given salt of radio-lead identical with that of the same salt of ordinary lead? Evidence on this point would go far to decide whether density or atomic volume is the more important thing in determining refractive index. A very careful study carried out with the help of Dr. W. C. Schumb at Harvard has, within the past few months, shown that, as a matter of fact, the refractive index of ordinary lead nitrate is identical with that of the nitrate of uranium-lead within one part in nearly twenty thousand-- a result which shows that density is a less important factor in determining refractive index than had been previously assumed.

Both these conclusions concerning light-that drawn from the spectra and that drawn from the refractive indices-have a yet more far-reaching interest, for they give us a further clue as regards the innermost nature of the atom. That part of the atom which determines its weight seems to have, at least in these cases, very little effect on that part of the atom which determines its behaviour towards light.

Immediately connected with the question of density of the solid salts is the question as to the densities of their saturated solutions, as well as to the extent of saturation. Fajans and Lembert had recently obtained results probably indicating that the molecular solubility of each kind of lead is the same, and that the densities of the solutions are different, the density of the radio-lead solution being less to an extent consistent with its smaller molecular weight. These results, however, left much to be desired in the way of accuracy, and needed verification. Therefore, a very careful investigation, begun at Harvard with the assistance of Schumb, before the appearance of Fajans's publication, furnished valuable knowledge on this point.

\section{Solubility of Two Kinds of Lead Nitrate."}

\begin{tabular}{|c|c|c|}
\hline cent. salt in saturated & & Uranium-lead \\
\hline solution $\left(25 \cdot 00^{\circ}\right) \quad \ldots \quad \ldots$ & $37 \cdot 342$ & $37 \cdot 280$ \\
\hline Grams lead per too grams & & \\
\hline $\begin{array}{l}\text { water } \\
\text { Molecular solubility per }\end{array}$ & $37 \cdot 28 \mathrm{r}$ & $37 \cdot 130$ \\
\hline grams wate & I.7993 & $\mathrm{I} \cdot 7989$ \\
\hline
\end{tabular}

Here, again, differences in weight alone are manifest, and these are proportional to the differences in the atomic weights; the molecular behaviour is essentially identical in the two sorts. Hence a difference in density between the two solutions must exist, exactly consistent with the difference in the atomic weights.

The identity in solubility might also be inferred from the impossibility of separating the two kinds of lead from each other by fractional crystallisation. This was predicted by Soddy, and tested by him and by others. Various vain attempts have been made to separate the different kinds of lead from one another,

3 The uranium-lead used in these determinations was a speoimen from Australia having the atomic weight $206^{\circ} 4^{\mathrm{r}}$, not quite like the earlier sample, but not different in important degree.

$$
\text { NO. } 2579 \text {, VOL. IO3] }
$$


but apparently when once they are mixed no chemical method can separate them, since the properties of the different kinds are so nearly alike. The latest attempt at the Gibbs Memorial Laboratory involved one thousand fractional crystallisations of the Australian lead nitrate, which is believed to contain both ordinary and uranium-radium lead. The extreme fraction of the crystals (representing the least soluble portion, if any difference in solubility might exist) gave within the limit of error the same atomic weight as the extreme fraction of the mother liquor (representing the most soluble portion), thus confirming the work of others in this direction.

When wires constructed of two different metals are joined, and the junction is heated, an electrical potential or electromotive force is produced at the junction. This property seemed, then, to be a highly interesting one to test in order to find out how great may be the similarity of the two kinds of lead. In fact, wires made of radio-active lead and ordinary lead tested in the Gibbs laboratory gave no measurable thermo-electric effect, the wires acting as if they were made of the same identical substance, although the atomic weights and densities were different. No other known case of this sort is known, so far as I am aware. The melting points of the two kinds of lead were likewise found, with the assistance of N. F. Hall, to be identical within the probable accuracy of the experiment.

Let us bring all these results together into one table, so that we may better grasp their combined significance.

Summed up in a few words, the situation appears to be this : At least two kinds of lead exist-one, the ordinary metal disseminated throughout the world, in non-uraniferous ores; another, a form of lead apparently produced by the decomposition of uranium, radium being one of the intermediate products. If we leave out of consideration the probably inessential difference in radio-activity, the two kinds are very closely, if not exactly, alike in every respect excepting atomic weight, density, and immediately related properties involving weight, such as solubility. Thorium-lead appears to be a third variety, with similar relations. Shall we call these substances different elements, or the same? The best answer is that proposed by Soddy, who invented a new name and called them "isotopes" of the same element.

Comparison of Properties of Different Kinds of Lead."

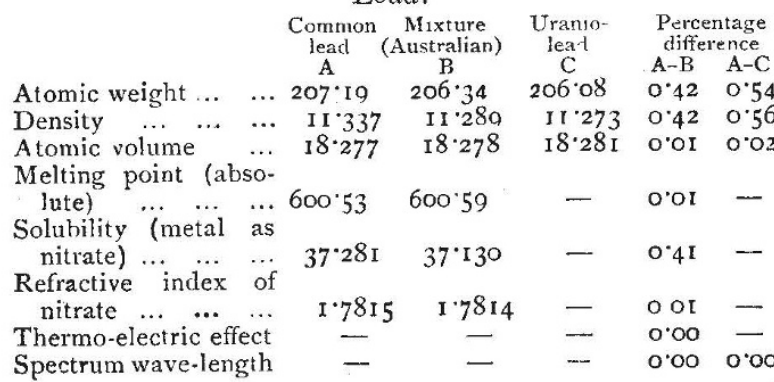

Since every new fact 'concerning the behaviour of the elements gives a new possible means of discovering something about their nature, and since these facts are of an especially significant kind, the anomaly is of more than passing interest, and mav be said to constitute one of the most interesting and puzzling situations now presented to the chemist who looks for the deeper meanings of things.

4 For the sake of better comparison, the values given are all those found at Harvard, since they all involved nearly the same material. The restlts of experime
identical. NO. 2579 , VOL. $\left.\mathrm{IO}_{3}\right]$
Many new queries arise in one's mind from a study of the data. Among them is a question as to the nature of ordinary lead, which possesses a less reasonable atomic weight than the radio-active variety. Why should this state of things exist?

Ordinary lead may be either a pure substance or else a mixture of uranium-lead with lead of yet higher atomic weight, perhaps 208. The latter substance might be formed, as Soddy points out, if thorium (over 232) lost six atoms of helium, and he and Hönigschmid have found quantitative evidence of its existence in thorium minerals.

After reviewing all the data, Prof. F. W. Clarke has brought forward an interesting and reasonable hypothesis explaining the difference between the several kinds of lead. He points out that, whereas we have every reason to believe that uranium- and thorium-lead are the results of disintegration of heavier atoms, ordinary lead may be imagined to be the product of a far earlier synthesis or evolution from smaller atcms. The hypothesis might be supported by the analogy of the synthesis and decomposition of organic substances, which by no means always follow similar paths; it seems to be consistent with most, if not all, of the facts now known.

On the other hand, may not the uniformity of ordinary lead and its difference from either of the radio-active leads be almost equally capable of interpretation in quite a different fashion? Whenever, in the inconceivably distant past, the element lead was evolved, it is scarcely to be supposed that uranium-lead and thorium-lead could have been entirely absent. The conditions must have been chaotic and favourable to mixture. Whe1, the two or more forms were mixed, none of the processes of Nature would separate them. Therefore they must appear æons afterwards in an equably mixed state on earth, constituting our ordinary lead. There may have been more than two forms of lead; but two forms, one possessing an atomic weight 206, and the other an atomic weight above 208, would account for all the facts. The identity in nature of all the common lead on earth might indicate merely that at one time all the matter now constituting the earth was liquid or gaseous in violent agitation, so that all the kinds of lead were thoroughly commingled before solidification. This explanation, if it could be confirmed, would furnish important evidence concerning the early history of planets. So far afield may a difference in weight amounting to two units in the twenty-fourth decimal place, between two kinds of atoms so small as to be far beyond the possible range of our most piercing means of actual observation, carry the inquiring investigator!

The true answers to these questions are not to be found by speculation such as that just detailed, however suggestive such speculation may be. They are to be found by careful observation. For example, the doubt as to the nature of ordinary lead can be decided only by discovering whether or not it may be separated into two constituents. Since weight (or mass) is the quality distinguishing between the several isotopes or kinds of lead, weight (or mass) must be made the basis of separation. Hence the only hope of separating isotopes of lead lies in the method of fractional diffusion, as has been already suggested by many other experimenters on this subject. Promising preliminary experiments preparatory to such an undertaking have already been begun at Harvard, and before long more light may be obtained.

The idea that other elementary substances also may be mixtures of two or more isotopes has been advanced by several chemists. Especially if ordinary lead should really be found tc be thus complicated, 
many, if not all, other elements should be tested in the same way. The outcome, while not in the least affecting our table of atomic weights so far as practical purposes are concerned, might lead to highly interesting theoretical conclusions.

How can such remote scientific knowledge, even if it satisfies our ever-insistent intellectual curiosity, be of any practical use? Who can tell? It must be admitted that the relationship is apparently slight as regards any immediate application, but one can never know how soon any new knowledge concerning the nature of things may bear unexpected fruit. Faraday had no conception of the electric locomotive or the power plants of Niagara when he performed those crucial experiments with magnets and wires that laid the basis for the dynamo. Nearly fifty years elapsed before his experiments on electric induction in moving wires bore fruit in a practical electric lighting system; and vet more years before the trolley-car, depending equally upon the principles discovered by Faraday, became an everyday occurrence. At the time of discovery, even if the wide bearing and extraordinary usefulness of his experiments could have been foreseen by him, they were certainly hidden from the world at large.

The laws of Nature cannot be intelligently applied until they are understood, and in order to understand them many experiments bearing upon the fundamental nature of things must be made in order that all may be combined in a far-reaching generalisation impossible without the detailed knowledge upon which it rests. When mankind discovers the fundamenıal laws underlving any set of phenomena, these phenomena come in much larger measure than before his control, and are applicable for his service. Until we understand the laws, all depends upon chance. Hence, merely from the practical point of view, concerning the material progress of humanity, the exact understanding of the laws of Nature is one of the most important of all the problems presented to man; and the unknown laws underlying the nature of the elements are obviously among the most fundamental of these laws of Nature.

Such gain in knowledge brings with it augmented responsibilities. Science gives human beings vastly increased power. This power has immeasurably beneficent possibilities, but it may be used for ill as well as for good. Science has recently been blamed by superficial critics, but she is not at fault if her great potentialities are sometimes perverted to serve malignant ends. Is not such atrocious perversion due rather to the fact that the ethical enlightenment of a part of the human race has not kept pace with the progress of science? May mankind be generous and high-minded enough to use the bountiful resources of Nature, not for evil, but for good, in the days to come!

\section{UNIVERSITY AND EDUCATIONAL INTELLIGENCE.}

BRIsTol.-In the university courses for training engineers in the United States and Germany a certain amount of business training is given, with the result that in these countries there are many more engineers directing and administering engineering concerns than is the case in Great Britain. At the suggestion of the Dean of the faculty of engineering of the University, Dr. Wertheimer, the Senate has now decided that in future the curriculum for the B.Sc. degree shall include attendance at a course dealing with book-keeping, methods of administering and organising works, elements of commercial law, depreciation, estimating, costing, and the writing of specifications.
Cambridge.-Major H. McCombie, lecturer in chemistry in Birmingham University, has been elected to a fellowship at King's College.

LEEDS.-The council of the University has accepted with regret the resignation of Dr. C. Lovatt Evans, professor of experimental physiology and experimental pharmacology, who is leaving the Leeds Medical School at the end of June next in order to undertake research work in the Department of Pharmacology and Biochemistry of the Medical Research Committee.

London.-Capt. J. R. Partington has been appointed as from April I, I9I9, to the newly established University chair of chemistry tenable at East London College. In Igro Capt. Partington was elected Beyer research fellow of the University of Manchester, and in $19 \mathrm{I}_{\mathrm{I}}$ he was awarded an $185 \mathrm{I}$ Exhibition scholarship. From I9II to 1913 he studied under Profs. Nernst and Planck at Berlin. In $1_{9} I_{3}$ he was appointed assistant lecturer and demonstrator in chemistry at Manchester, and, having served in the Army from I914-16, he was recalled to take charge of research in the Ministry of Munitions Inventions Department. His principal publications are "Higher Mathematics for Chemical Students" and "A "Text-book of Thermodynamics."

It can now be announced that the anonymous donor who in rorr presented to the University the sum of $30,000 l$. for the erection of a school of architecture, a department of eugenics, and sculpture studios at the college is Sir Herbert H. Bartlett, Bart. The School of Architecture and the Department of Eugenics have been already completed, and the Sculpture Studios, towards the cost of which Sir Herbert Bartlett has presented an additional sum of roool. will be put in hand immediately.

An offer by Mr. G. S. Baker of 5 ool. for the foundation at University College of a prize for the encouragement of botanical research to be named after his daughter, the late Dr. Sarah M. Baker, an old student and member of the staff of the college, has been accepted by the Senate with thanks.

Owing to ill-health, Prof. Vaughan Harley has resigned the chair of pathological chemistry, which he has held for twenty-three years.

The degree of D.Sc. in biochemistry has been conferred on Mr. E. C. Grey, an internal student, of the Lister Institute of Preventive Medicine, for a thesis entitled "The Enzymes of B. coli communis."

Mr. A. P. McMullen, senior science master, Royal Naval College, Dartmouth, has been appointed Adviser on Education, Admiralty.

THE Pharmazeutische Zeitung reports the following changes in German botanical chairs:-Prof. Ludwig Jost, of Strasburo. succeeds at Heidelberg Prof. G. Klebs, who died last October in his sixty-first year, and Dr. W. Ruhland, of Halle, succeeds Prof. von Vöchting at Tübingen.

IT is announced in Science that the Carnegie Corporation of New York has voted a grant of roo,oool. to the Medical Department of Queen's University, Kingston, Ont. This grant is related to that in the will of Dr. James Douglas, New York, and is conditional on an additional roo,oool. being raised.

THE committee of the Summer School of Civics and Eugenics has arranged to hold its second school in August next, during the first two weeks. The centre selected for the meeting this year is Cambridge. The programme will fall into two portions, the first week being devoted to a preparatory course dealing with the scientific bases of educational and social work, and the lectures of the second week with special applications of civics and eugenics

NO. 2579 , VOL. IO3] 